\title{
Performance of resident nurses in obstetrics on childbirth care
}

Ariane Teixeira de Santana 1

https://orcid.org/0000-0001-6264-7115

Ridalva Dias Martins Felzemburgh 2

https://orcid.org/0000-0003-0295-9998

Telmara Menezes Couto 3

https://orcid.org/0000-0001-6836-8563

Lívia Pinheiro Pereira 4

https://orcid.org/0000-0003-3587-6523

1-4 Escola de Enfermagem. Universidade Federal da Bahia. Rua Dr. Augusto Viana, s.n. Salvador, BA, Brasil. CEP: 40.110-060. E-mail: ariane.tds@gmail.com

\begin{abstract}
Objectives: to describe good practices on childbirth care and obstetric interventions performed by resident nurses in obstetrics during the obstetric childbirth risk at a public maternity hospital in Salvador.

Methods: a descriptive cross-sectional study with a quantitative approach, based on the of 102 parturients, between February and April 2016. The data collection was performed through the collection of information on clinical files for analysis by using descriptive statistics with absolute and relative frequencies for the evaluated categorical variables.

Results: it was observed that 100.0\% of the women used some kind of non-pharmacological method for pain relief, although the method of choice was to take a hot bath; $99.0 \%$ of the women drank liquids; $94.0 \%$ had the presence of a companion of free choice; $99.0 \%$ walked during labor; $100.0 \%$ had the freedom to choose a position during childbirth. It is noteworthy that no woman in this study was submitted to episiotomy, and more than $70.0 \%$ were not submitted to any obstetric intervention.

Conclusions: the Programa de Residência em Enfermagem (Residency Nursing Program) an important point in the childbirth humanization process is directly associated to the increase in the normal childbirth rates, the highest use on good practices in childbirth care, and the reduction on obstetric interventions.

Key words Humanized childbirth, Obstetric nurse, Childbirth, Labor, Maternal and child health
\end{abstract}




\section{Introduction}

The current conjuncture of obstetric care in Brazil presents an epidemiological scenario with high rates of maternal and perinatal mortality in an indiscriminated use of interventions and high cesarean section rates. In this context, the Ministry of Health (MH) released a Programa Nacional de Residencia em Enfermagem Obstétrica (National Residency in Obstetric Nursing Program) in 2012, a program with an objective to encourage higher education institutes to train specialized nurse professionals in obstetrics. This action seeks to contribute the qualification in obstetric care by training nurses for humanized care with the purpose of improving and modifying the model in women's health care, especially during their pregnancy, childbirth and post-partum.1,2

In the state of Bahia, the Residencia em Enfermagem Obstétrica (Residency in Obstetric Nursing) was implemented in 2012 through a partnership between the Ministries of Health and Education along with the Universidade Federal da Bahia (Federal University of Bahia). With the premise of Post Graduating in the latu sensu modality, by training nurses through practical education in order to work in a humanized and integrated manner, caring for women and newborns and developing skills to follow the physiological childbirth process, as indicated by the orientations of good practices in obstetric care, supported by scientific evidence and by the strategy of the Rede Cegonha (Stork Network). ${ }^{2}$

The qualified and competent obstetric nurses follow the physiological childbirth process in contributing to its natural evolution, recognizing and correcting the deviations from normality, and referring those that need specialized care. 3,4

In 1996, the World Health Organization (WHO) developed a classification on common practices in the conduction of obstetric childbirth risks instructing on what should and should not be done in the labor process. This classification was based on scientific evidence concluded in researches from all over the world. 5 Therefore, it can be defined that good obstetric practices as those proven to be beneficial and based on scientific evidence by respecting the physiological labor process and presenting the best results for mothers and newborns.

The WHO considers that through less interventionist characteristic care, the obstetric nurses and midwives are the most adequate professionals to accompany pregnancies and obstetric childbirth risks. 5

According to a review published in Cochrane in
2013, most women who were assisted during labor were by a midwife or an obstetric nurse in which presented better results compared to those who were assisted by physicians only. Their presence in assisting childbirth, contributes significantly to humanized care, promoting less interventions and more maternal satisfaction. 6

Team work between obstetric nurses or midwives with physicians on shift greatly decreases the number of cesarean sections. The results of a research carried out at the University of California, San Francisco School of Medicine, with 4,351 parturients revealed that this model in care drastically decreased the cesarean section rates in nulliparous parturients and a slight increase in the rates on vaginal birth after cesarean (VBAC). ${ }^{7}$ In this model of group work, in cases of low risk, it is suggested that nurses should provide care, and in cases of high risk, the care should be provided by obstetric physicians allowing a less interventionist approach.7

A simple replacement of the physician for an obstetric nurse does not necessarily result in humanized care. It is noteworthy that the action of this professional is inserted in a new proposition of care and enables to change the model in care. $3,4,5$

With the purpose of contributing to the discussion about care given by the obstetric nurses during labor and obstetric childbirth risks, this study has a goal to describe good practices in care and obstetric interventions made by resident nurses in obstetrics during obstetric childbirth risk in a public maternity in Salvador.

\section{Methods}

This is a descriptive cross-sectional study with a quantitative approach, carried out between February and April, 2016, using secondary data found in medical files. The study was developed at a Public Maternity in Salvador city in Bahia State. We selected 160 medical files from a total of 307 childbirths assisted by resident nurses in obstetrics. 147 medical files were not analyzed because there were no signatures or stamps from the responsible preceptor for the care along with the resident. Of the 160 medical files, 58 were excluded from the research due to the lack of information regarding to the essential variables for answering the questions in this study. 102 medical files were analyzed, this is equivalent to $34 \%$. The selection of the medical files for this research was randomized and the elected medical files corresponded to childbirth care between January 2014 and May 2015 
As the criteria for eligibility in this study, we used data from puerperals' medical files whose childbirths were assisted by resident nurses in obstetrics, in which lacked clinical or obstetric pathologies, with gestational age between 37 and 41 weeks and 4 days, and besides a singleton pregnancy.

The variables analyzed in this study were: good practices and obstetric interventions during labor and childbirth. Good practices are defined as: fluids or food intake during labor or childbirth, the use of non-pharmacological methods to relieve pain, the presence of a companion of choice, mobility during all the stages of labor and monitoring the progress of labor through a partogram. Good practices assessed during childbirth were: the use of vertical position, late clamping of the umbilical cord, skin-to-skin contact and breastfeeding in the delivery room. The following interventions during labor was considered: the use of venous catheter, oxytocin to accelerate labor and amniotomy. Regarding to interventions during childbirth, lithotomy and episiotomy were also assessed variables.

For statistical analysis, the data collected was organized in the Microsoft Excel version 2011 spreadsheets and analyzed through simple descriptive statistics presenting absolute values and its respective percentage values.

All the proportions, tests, confidence intervals and models were estimated considering the complex characteristics of the sample. A descriptive statistic was used with relative and absolute frequencies, strata, conglomerate and weighs. The statistic program used was EPI INFO, version 3.5.2 Centers for Disease Control and Prevention (CDC), United States.

This research adhered to the criteria and requirements of the Resolution n. 466/12 of the Conselho Nacional de Saúde (National Health Council) that defines the recommendations and standard procedures for human researches was filed in the Research Ethics Committee at the Escola de Enfermagem da Universidade Federal da Bahia, and was approved by the document number 1.399 .789

\section{Results}

The analysis of the obtained data intended to identify the defined variables for this study. A set of values was emphasized in which portrayed a profile of assistance given by the resident nurses.

According to the social demographic data, we observed that the mean age group of the participants in this research was around 22 years old. The results showed that the women had a mean of 8 years of schooling. In relation to skin color, $40.2 \%$ of the women were black, most of which $(8.8 \%)$ were unemployed. As to marital status, $21.6 \%$ of the women were in a stable union. $94.1 \%$ of the women were from Salvador city. In the medical files, $57.8 \%$ had no information about their race, $76.5 \%$ had no information about their occupation, and $61.8 \%$ had no information about their marital status.

As to obstetric aspect, $99.0 \%$ of the women had prenatal care. In relation to childbirth, $55.1 \%$ of the women had one or more. The mean of the gestational age was 38 weeks and 4 days (Table 1).

In terms of feeding, $99.0 \%$ of the women had fluid intake during labor. As for the partogram, $94.9 \%$ of the women had their childbirth progression monitored by this instrument. In relation to having a companion, $92.8 \%$ of parturients had the presence of a companion of their free choice during labor. Nearly $99.0 \%$ of the women moved around during labor, walking or crouching.

According to the results of using good obstetric practices during labor, $100.0 \%$ of the women used some type of non-pharmacological method to relieve the pain during labor. The methods were the birthing stool, bobath ball, hot bath, massages and others that include breathing, music therapy, aromatherapy, crouching and vocalization. The most used nonpharmacological method was the hot bath $(81.6 \%)$. Primiparous women used the non-pharmacological methods more than those who had given birth before, with the exception of the bobath ball (Table 2).

As for obstetric interventions during labor and childbirth, we observed that in $20.4 \%$ of the women had peripheral venipuncture, and in $18.4 \%$ oxytocin was administered during labor. However, both interventions were more prominent in women who had given birth before. Amniotomy was performed in $5.1 \%$ of the parturients; there were no registration of episiotomy in any of the labors in this study. (Table 3).

The results of the variables for good practice during labor showed that $100.0 \%$ of the women had their rights respected and were able to position themselves freely during labor. Besides, in $99.9 \%$ of them had skin to skin contact between the mother-baby binomial and $95.9 \%$ had late clamping of the umbilical cord. $97.0 \%$ of the women were able to breastfeed in the first hour of the baby's life, (Table 4).

In regards to the position during childbirth, $57.2 \%$ of the pregnant women gave birth in a semiseated position, followed by $18.4 \%$ crouching position. None of the primiparous in this sample gave 
Table 1

\begin{tabular}{lcc}
\hline Obstetric data. & & \\
\hline Characteristics & 39.4 & $(39.2-40)$ \\
\hline Median Gestational Age (IQI)* & 46 & 44.9 \\
Parity - $\mathrm{n}(\%)$ & 56 & 55.1 \\
$\quad$ Primiparous & & \\
$\quad$ Women with more than one childbirth & 101 & 98.98 \\
Had prenatal care - $\mathrm{n}(\%)$ & 1 & 1.02 \\
$\quad$ Yes & & \\
No & &
\end{tabular}

* IQI= Interquartile Intervals.

Table 2

\begin{tabular}{|c|c|c|c|c|c|c|}
\hline \multirow[t]{2}{*}{ Characteristics } & \multicolumn{2}{|c|}{ Primiparous } & \multicolumn{2}{|c|}{$\begin{array}{l}\text { Women with more } \\
\text { than one childbirth }\end{array}$} & \multicolumn{2}{|c|}{ All women } \\
\hline & $\mathrm{n}$ & $\%$ & $\mathrm{n}$ & $\%$ & $\mathrm{n}$ & $\%$ \\
\hline \multicolumn{7}{|l|}{ Feeding } \\
\hline Yes & 46 & 100.0 & 55 & 98.2 & 101 & 99.0 \\
\hline No & 0 & - & 1 & 1.8 & 1 & 1.0 \\
\hline \multicolumn{7}{|c|}{ Use of partogram } \\
\hline Yes & 45 & 97.8 & 50 & 89.3 & 95 & 94.9 \\
\hline No & 1 & 2.2 & 6 & 10.7 & 7 & 5.1 \\
\hline \multicolumn{7}{|c|}{ Companion during labor } \\
\hline Yes & 44 & 95.7 & 49 & 87.5 & 93 & 92.8 \\
\hline No & 2 & 4.3 & 7 & 12.5 & 9 & 7.2 \\
\hline \multicolumn{7}{|l|}{ Walking } \\
\hline Yes & 46 & 100.0 & 55 & 98.0 & 101 & 99.0 \\
\hline No & 0 & - & 1 & 1.8 & 1 & 1.0 \\
\hline \multicolumn{7}{|l|}{ Birthing stool } \\
\hline Yes & 27 & 58.7 & 19 & 33.9 & 46 & 44.9 \\
\hline No & 19 & 41.3 & 37 & 66.1 & 56 & 55.1 \\
\hline \multicolumn{7}{|l|}{ Hot bath } \\
\hline Yes & 40 & 87.0 & 42 & 75.0 & 82 & 81.6 \\
\hline No & 6 & 13.0 & 14 & 25.0 & 20 & 18.4 \\
\hline \multicolumn{7}{|l|}{ Ball } \\
\hline Yes & 10 & 21.7 & 14 & 25.0 & 24 & 22.5 \\
\hline No & 36 & 78.3 & 42 & 75.0 & 78 & 77.5 \\
\hline \multicolumn{7}{|l|}{ Massage } \\
\hline Yes & 19 & 41.3 & 19 & 33.9 & 38 & 36.7 \\
\hline No & 27 & 58.7 & 37 & 66.1 & 64 & 63.3 \\
\hline \multicolumn{7}{|l|}{ Other methods } \\
\hline Yes & 27 & 58.6 & 24 & 42.9 & 51 & 50.0 \\
\hline No & 19 & 41.4 & 30 & 57.2 & 51 & 50.0 \\
\hline
\end{tabular}


birth in a supine position or lying sideways. There were no registrations of the lithotomic position in any of these labors (Table 5).

The percentage by using good practices in care by resident nurses has shown to be superior when compared to obstetric interventions performed during labor by these professionals.

Table 3

Obstetric interventions performed during labor and childbirth.

\begin{tabular}{|c|c|c|c|c|c|c|}
\hline \multirow[t]{2}{*}{ Characteristics } & \multicolumn{2}{|c|}{ Primiparous } & \multicolumn{2}{|c|}{$\begin{array}{l}\text { Women with more } \\
\text { than one childbirth }\end{array}$} & \multicolumn{2}{|c|}{ All women } \\
\hline & $\mathrm{n}$ & $\%$ & $\mathrm{n}$ & $\%$ & $\mathrm{n}$ & $\%$ \\
\hline \multicolumn{7}{|c|}{ Peripheral venous catheter } \\
\hline Yes & 8 & 17.4 & 14 & 25.0 & 22 & 20.4 \\
\hline No & 38 & 82.6 & 42 & 75.0 & 80 & 79.6 \\
\hline \multicolumn{7}{|l|}{ Oxytocin } \\
\hline Yes & 7 & 15.2 & 13 & 23.2 & 20 & 18.4 \\
\hline No & 39 & 84.8 & 43 & 76.8 & 82 & 81.6 \\
\hline \multicolumn{7}{|l|}{ Amniotomy } \\
\hline Yes & 6 & 13.0 & 1 & 1.8 & 7 & 5.1 \\
\hline No & 40 & 87.0 & 55 & 98.2 & 95 & 94.9 \\
\hline \multicolumn{7}{|l|}{ Episiotomy } \\
\hline No & 46 & 100.0 & 56 & 100.0 & 102 & 100.0 \\
\hline
\end{tabular}

Table 4

\begin{tabular}{|c|c|c|c|c|c|c|}
\hline \multirow[t]{2}{*}{ Characteristics } & \multicolumn{2}{|c|}{ Primiparous } & \multicolumn{2}{|c|}{$\begin{array}{l}\text { Women with more } \\
\text { than one childbirth }\end{array}$} & \multicolumn{2}{|c|}{ All women } \\
\hline & $\mathrm{n}$ & $\%$ & $\mathrm{n}$ & $\%$ & $\mathrm{n}$ & $\%$ \\
\hline \multicolumn{7}{|c|}{ Companion during labor } \\
\hline Yes & 45 & 97.8 & 51 & 91.1 & 96 & 96.0 \\
\hline No & 1 & 2.2 & 5 & 8.9 & 6 & 4.1 \\
\hline \multicolumn{7}{|c|}{ Free position for childbirth } \\
\hline Yes & 46 & 100.0 & 56 & 100.0 & 102 & 100.0 \\
\hline \multicolumn{7}{|l|}{ Late clamping } \\
\hline Yes & 42 & 91.3 & 54 & 96.5 & 96 & 95.9 \\
\hline No & 4 & 8.7 & 2 & 3.6 & 6 & 4.1 \\
\hline \multicolumn{7}{|c|}{ Skin-to-skin contact } \\
\hline Yes & 44 & 95.7 & 56 & 100.0 & 100 & 99.9 \\
\hline No & 2 & 4.3 & 0 & - & 0 & 0.1 \\
\hline \multicolumn{7}{|c|}{ Breastfeeding in the delivery room } \\
\hline Yes & 43 & 93.5 & 54 & 96.5 & 97 & 97.0 \\
\hline No & 3 & 6.5 & 2 & 3.6 & 5 & 3.0 \\
\hline
\end{tabular}




\begin{tabular}{|c|c|c|c|c|c|c|}
\hline \multirow[t]{2}{*}{ Characteristics } & \multicolumn{2}{|c|}{ Primiparous } & \multicolumn{2}{|c|}{$\begin{array}{l}\text { Women with more } \\
\text { than one childbirth }\end{array}$} & \multicolumn{2}{|c|}{ All women } \\
\hline & $\mathrm{n}$ & $\%$ & $n$ & $\%$ & $\mathrm{n}$ & $\%$ \\
\hline \multicolumn{7}{|l|}{ Crouching } \\
\hline Yes & 9 & 19.6 & 11 & 19.6 & 20 & 18.4 \\
\hline No & 37 & 80.4 & 45 & 80.4 & 82 & 81.6 \\
\hline \multicolumn{7}{|l|}{ Gaskin } \\
\hline Yes & 7 & 15.2 & 3 & 5.4 & 10 & 8.2 \\
\hline No & 39 & 84.8 & 53 & 94.6 & 92 & 91.8 \\
\hline \multicolumn{7}{|l|}{ Semi- seated } \\
\hline Yes & 27 & 58.7 & 31 & 55.4 & 58 & 57.2 \\
\hline No & 19 & 41.3 & 25 & 44.6 & 44 & 42.8 \\
\hline \multicolumn{7}{|c|}{ Semi-lying down } \\
\hline Yes & 0 & - & 6 & 10.7 & 6 & 4.1 \\
\hline No & 46 & 100.0 & 50 & 89.3 & 96 & 95.9 \\
\hline \multicolumn{7}{|l|}{ Lateral Position } \\
\hline Yes & 0 & - & 2 & 3.6 & 2 & 0.04 \\
\hline No & 46 & 100.0 & 54 & 96.4 & 100 & 99.9 \\
\hline \multicolumn{7}{|l|}{ Birthing stool } \\
\hline Yes & 5 & 10.9 & 3 & 5.4 & 8 & 6.2 \\
\hline No & 41 & 89.1 & 53 & 94.6 & 94 & 93.8 \\
\hline \multicolumn{7}{|c|}{ Lithotomy Position } \\
\hline No & 46 & 100.0 & 56 & 100.0 & 102 & 100.0 \\
\hline
\end{tabular}

\section{Discussion}

The results in this study allowed us to identify and describe good practices in labor care and obstetric interventions performed by resident nurses in obstetrics during the assistance in obstetric childbirth risk. Incorporating good practices in labor care and the reduction of unnecessary interventions are recommended by the WHO. 5

The current recommendations from the Ministry of Health to manage labor include the supply of fluids, the encouragement to adopt vertical positions and the freedom of movement, seeking to increase maternal comfort and to facilitate the labor progression; and the use of non-pharmacological methods to relieve pain, such as hot showers or baths, massages and the like. ${ }^{8}$ These are accessible, non-invasive and low-cost technologies, which can be offered by all health services.

In this study, the use of good practices, such as feeding during labor, movement, the use of nonpharmacological methods to relieve pain and monitoring the labor evolution through the partogram, presented varied incidences and values above $90.0 \%$, this is more frequent in primiparous.
The sociodemographic profile evidenced young women with at least eight years of schooling, who were in a stable union and were unemployed. However, it is important to highlight that this information was not found in the medical files, a fact that made it difficult to define this profile more accurately, since many medical files were not filled out completely.

Evidences indicate several benefits of the presence of a companion during labor, such as, a decrease in time of labor, less need for medication or analgesia, as well as for operative or instrumental delivery, higher Apgar scores, higher breastfeeding rates, women feeling more confident, in control and communicating during childbirth and being satisfied, besides, a lower vulnerability to obstetric violence. $5,9,10$

A continued support from a companion for a woman in labor and at childbirth is a safe and highly effective intervention to improve maternal and neonatal outcomes, with high rates of maternal satisfaction, low cost, and in addition, women have this right. 5

The data presented satisfactory results $(92.8 \%)$ in relation to companions being present at the time 
of labor and $(96.0 \%)$ at childbirth. The results presented here, unfortunately, do not reflect many women's reality. According to the latest cohort data from Nascer no Brasil (Born in Brazil), 24.5\% of the women had no companion with them during labor, $18.8 \%$ had a continuous companion, $56.7 \%$ had a partial companion, yet it shows that a lot of women in Brazil cannot count on the presence of a companion during labor or childbirth. 11

The use of the partogram during labor in this study was to follow most of the childbirths, $94.9 \%$ of the women had their childbirths accompanied by the partogram. To fill out the partogram information, the institution that verified this study, began a minimum uterine dilation of $6 \mathrm{~cm}$ and followed the model recommended by the WHO. The use of this graphic representation of labor allowed to monitor its evolution, diagnosis of alterations and indicates on making decisions. 8

A systematic review from the Cochrane 12 library with 6,187 parturients synthesized the findings of five clinical trials which assessed whether or not the use of a partogram. The conclusion was that there were no sufficient evidences to recommend a routine use of the partogram as part of the follow-up on childbirth, but it was emphasized that clinical trials are necessary to establish the efficiency of its use. However, since rate reductions were found in unnecessary cesarean section and as it a low-cost measurement, it is possible to be useful in lowerclass populations. The researchers recommend caution in its use. 12

Fasting during labor is an old recommendation based on the concern of risks in aspiration of gastric contents in case of a general anesthesia is required, a rare event, especially in women with low-risk pregnancies. 13

Based on the necessity to maintain the woman's hydration and adequate caloric intake during childbirth, as well as to offer her comfort and well-being, in several locations, intake of light food or fluids during labor was allowed. ${ }^{8}$ The results showed that $99.0 \%$ of the women who had fluids intake during childbirth had a significant value which seemed to be in agreement with the current scientific recommendations. 10 The recommendations for food or fluid intake during labor should be analyzed according to current knowledge, evaluating its risks and benefits.

In a meta-analysis that included five studies involving 3,130 women of obstetric risk for the need of anesthesia, concluded that there is no reason to restrict liquids and food for these women in labor. According to the authors, there are no studies on women at high-risk for complications, and therefore, there are no evidences that support this practice of fasting routine. 14

Regarding to the freedom of movement in labor, $99.0 \%$ of the women walked around, and among the primiparous, all of them opted for walking during labor. The WHO recommends that all women should be encouraged to move around and adopt the positions they find most comfortable for labor, since the supine position during the first stage of labor may have adverse physiological effects both for the mother and fetus in the labor progression. ${ }^{5}$

A systematic review published in the Cochrane15 Library comprised 25 randomized clinical trials with 5,218 women regarding maternal positions and walking during the first period of labor. The results pointed out that there are important scientific evidences that walking and vertical positions in the active phase of labor reduce the duration by approximately one hour and 22 minutes less when compared to the reclining position. Therefore, it reduces the risk of cesarean section and the necessity of epidural analgesia. It is recommended that, if possible, women should be encouraged and supported to walk around and be in vertical positions of their choice, and thus, it may improve the progress of labor and lead to a better maternal-fetal outcomes. 15

Physiologically, it seems much better for the fetus and for the mother to keep moving around during labor because the action of gravity on the fetal descent and trajectory is favored by the vertical position of the parturient in labor and at childbirth. In addition, this position prevents the compression of the great maternal vessels, improving the blood flow. 16

The non-pharmacological methods of pain relief are widely known throughout the world and there is a wide variety of non-pharmacological methods. According to WHO, they should be offered to all women during labor care, considering them as proven practices in being useful and should also be encouraged. 5

A systematic review 17 with 11 clinical trials report the various options of non-pharmacological methods such as hot baths, Swiss ball perineal exercises, breathing exercises, relaxation, massage, acupuncture, electro-stimulation, subcutaneous injection of distilled water, and among others. It is asserted that these practices offer comfort and allow the parturients' a freedom to choose. 17

In this study, the use of some non-pharmacological method to relieve pain during labor was almost $100.0 \%$ for the women, demonstrating women's willingness to have a more active childbirth. The hot 
bath was the most used non-pharmacological method by women $(81.6 \%)$, either by itself or associated to other methods such as a massage $(36.7 \%)$, bobath ball $(22.5 \%)$, or other methods that included breathing, music therapy, aromatherapy, crouching and vocalization (49.9\%).

An experimental, randomized intervention and blind clinical trial 18 with 15 obstetric low-risk parturient women, investigated the non-pharmacological interventions for pain relief. It was concluded that the use of non-pharmacological interventions to relieve pain during the active phase of labor, such as, the hot bath alone and the combined of the Swiss ball, reduced the score on pain indicated by parturients, in which promoted relaxation and reduced the anxiety. 18

Another systematic review 19 that analyzed 22 studies evaluated non-pharmacological methods as a therapeutic intervention. Ratifying that massage, aromatherapy, immersion bath, acupuncture and acupressure are effective methods to relieve the pain in labor, because, in addition to diminishing painful perception, reduce levels of anxiety and stress. Among these, the most effective one was the massage, especially when applied in the first phase of labor. 19

The data did not present high rates on obstetric interventions; peripheral venous puncture was the most frequent, $20.4 \%$. In addition, $18.4 \%$ of the women used oxytocin during labor, and both interventions were more present in women who had deliveries before. Amniotomy was performed in $5.1 \%$ of the parturients. No incidences of episiotomy were found.

In Brazil, childbirth and birth care is in its largely interventionist. In this perspective, childbirth is treated as a medical event, in which the woman's body is believed to be faulty and, in order to work properly, it is necessary, routinely interventions are needed. 20

According to the cohort data on Nascer no Brasil (Born in Brazil) was carried out with 23.940 puerperal women, the use of good practices during labor occurred in less than $50 \%$ of the women included in the study, which the occurrence was even less frequent in the North, Northeast and Mideast regions. On the other hand, obstetric interventions proved to be excessive. The use of oxytocin and amniotomy was $40 \%$, higher in the public sector and in women with lower schooling level. The Kristeller maneuver, episiotomy and lithotomy were performed in $37 \%, 56 \%$ and $92 \%$ of the women, respectively. The results showed that only $5.6 \%$ of the low-risk parturients and $3.2 \%$ of the primiparous of the sample gave birth in a natural form. ${ }^{1}$

Another study carried out with 655 primiparous women sought to compare the collaborative model (integration in care between the obstetric nurse and the physician) and the traditional model (focused on the physician), showed that there were significant differences in the collaborative model. In this model, there was less use of oxytocin $(50.2 \%$ in the collaborative model versus $65.5 \%$ in the traditional model), for artificial rupture of the membranes $(54.3 \%$ in the collaborative model versus $65.9 \%$ in the traditional model) and of the episiotomy rate $(16.1 \%$ in the collaborative model versus $85.2 \%$ in the traditional model). ${ }^{21}$

In this present study did not present cases of episiotomy, which demonstrated a strengthening of good practices in childbirth care by resident nurses in obstetrics at the studied institution. It is important to emphasize that nurses, historically, have less interventionist training than medical professionals, which is a facilitator in a more physiological approach. The current WHO recommendation is not to prohibit episiotomy, but rather to restrict its use by applying criteria for its performance. However, the rate of episiotomy should not exceed $10 \%$, which this rate was found in an English randomized clinical trial. 5

It is important to ratify that more than $70.0 \%$ of the women in this study did not receive any type of intervention during their labor and childbirth, in other words, they had natural and physiologic childbirth.

In this study, all the women had the freedom of choosing the position during childbirth, the highest prevalence was of the vertical positions $(57.2 \%$ semi-seated, followed by $18.4 \%$ crouching position). Women can adopt any position that is pleasant to them, preferably avoiding long periods in the dorsal position. They should be stimulated in experiencing what is most comfortable and their choices should be supported. The lateral position, vertical (seated, semi-seated, crouching or kneeling) and on all fours, when they were in the second stage of labor, these presented greater advantages than the dorsal position. The vertical position causes less discomfort and pulling difficulties, less pain during labor, less vaginal or perineal trauma, and incision infections. 5,15

The dorsal position is widely used in the second period of labor, since it favors the service provider's vision at the time of the fetal expulsion, on the contrary to scientific evidence on this non-physiological position. It is known that in this position there is a reduction in uterine efficiency and conse- 
quently decreases placental blood flow. A systematic review 23 with 20 randomized clinical trials of 6.135 women pointed out that the vertical or lateral positions were associated in reducing the duration of the second period of childbirth, reducing fetal heart rate abnormalities, increasing the diameter of the childbirth canal, improving uterine circulation that allows muscle fibers to fulfill their contractile function more efficiently, as well as reducing reports on severe pain and episiotomies. However, there was greater blood loss, but no significant clinical repercussions. 22

Care for healthy newborns in the delivery room basically includes warming and drying to promote warmth, skin-to-skin contact with the mother, and stimulate breastfeeding. However, what is seen in most delivery rooms are various interventions with the newborns. (Procedures used unnecessarily to healthy newborns, such as, early clamping of the umbilical cord, routinely aspiration, distancing the mother and baby in the first hour of life). Such early interventions influence the physiology and behavior of the mother-baby binomial. Skin-to-skin contact helps regulate the temperature of the newborn, the colonization by maternal microorganisms, and adjusts the newborn's breathing and crying.3,5

Skin-to-skin contact shortly after birth improves the neonatal outcomes in relation to crying and improves cardio-respiratory stability, besides, increases the success of breastfeeding within the first hour of life without any apparent short and long term negative effects, and should be recommended. ${ }^{23} \mathrm{~A}$ systematic review with 297 neonates, which included seven studies, showed that late clamping of the umbilical cord seems to be associated to a lower necessity of transfusion and less intraventricular hemorrhage. ${ }^{24}$

There is still a great variation in the practices used in the care of healthy newborns in Brazil. A national cohort revealed that skin-to-skin contact between the mother and the newborn soon after birth was more frequent in the South Region $(32.5 \%)$, as the offering maternal breast in the delivery room $(22.4 \%)$. Although, the proportions of offering maternal breast in the delivery room are still low in all the regions in Brazil (16.1\%), the lowest proportion is in the Northeast Region (11.5\%). In hospitals with the title Amigo da Criança (Child's Friend), the newborn being breastfed in the delivery room was significantly higher, but still low (24\%). The distancing of the baby from the mother also varied significantly among the Regions in Brazil. In the North Region, $87.3 \%$ of the newborns were to join the mother, while in the Southeast only $61.4 \%$ were joined. 25

The presence of resident nurses in obstetrics in parturient care contributes in a qualified and humanized manner to the accession of clearly benefit practices in women and newborns' care. The data from this study shows that the use of good practices, as recommended by the WHO and the Ministry of Health are being widely applied, as well as the discreet use of the intervention during labor and childbirth, allowing greater number of women to experience more physiological childbirths.

The current obstetric care model used in the country is still under development according to the biomedic model, in which interventions are prioritized in the physiological process of labor and childbirth, characterized as a technocratic model. The results showed the commitment of the obstetric and resident nurses, who integrate childbirth and birth care at the institution where this study was carried out in the attempt of adapting to the humanized model in the perspective of practices based on scientific evidences. Demonstrating support for the humanized model of childbirth care in most practices.

The Programa de Residência em Enfermagem Obstétrica (Obstetric Nursing Residency Program) as a strategy to qualify professionals, enabling a reduction in the number of unnecessary obstetric interventions, directly reflecting on the improvement of women and newborn's health.

It is important that health managers provide the conditions to implement the assistance model which includes obstetric nurse and midwife in low-risk childbirth care, presenting advantages in relation to the reduction of interventions and women's full satisfaction. The transformation in the obstetric care model is a current challenge that requires efforts from managers and health professionals.

The active role of obstetric nurse and midwife is a common point in the health systems of countries that present the best indicators on childbirth and birth care. Thus, it is observed in previous studies and we ratified in the results of this research the presence of obstetric nurse, as an important point in the humanization process in childbirth, directly associating to the increase of normal childbirth rates, the greater use of good practices in childbirth care and the reduction of obstetric interventions. 


\section{References}

1. Carmo ML, Esteves APP, Madeira RMSD, Filha MMT, Dias MAB, Nakamura-Pereira M, Bastos MH, Gama SGN. Intervenções obstétricas durante o trabalho de parto e parto em mulheres brasileiras de risco habitual. Cad Saúde Pública. 2014; 30( Supl. 1): S17-S32.

2. Brasil. Ministério da Saúde. Secretaria de Gestão do Trabalho e da Educação na Saúde. Portaria conjunta n ${ }^{\circ} 5$, de 31 de outubro de 2012. Nacional de Bolsas para Residência em Enfermagem Obstétrica. Brasília, DF; 2012.

3. Brasil. Ministério da Saúde. Humanização do parto e do nascimento/Ministério da Saúde. Brasília, |DF; 2014.

4. Merighi, MA B, Gualda, DMR. O cuidado à saúde materna no Brasil e o resgate do ensino de obstetrizes para assistência ao parto. Rev Latino-am Enf. 2009; 17 (2): 26570 .

5. WHO (World Health Organization). Maternal and Newborn Health/Safe Motherhood Unit. Care in normal birth: a practical guide. Geneva; 1996.

6. Sandall J, Soltani H, Gates S, Shennan A, Devane D. Midwife-led continuity models versus other models of care for childbearing women. Cochrane Database Syst Rev. 2013; (8): CD004667.

7. Rosenstein MG, Nijagal M, Nakagawa S, Gregorich S, Kuppermann M. The association of expanded access to a collaborative midwifery and laborist model with cesarean delivery rates. Obstetr Gynecol. 2015; 126 (4): 716-23.

8. Brasil. Ministério da Saúde. Secretaria de Políticas de Saúde. Área Técnica de Saúde da Mulher. Parto, aborto e puerpério: assistência humanizada a mulher. Brasília, DF; 2002.

9. Bruggemann MO, Oliveira ME, Martins HEL, Alves MC, Gayeski ME. A inserção do acompanhante de parto nos serviços públicos de saúde de Santa Catarina, Brasil. Esc Anna Nery. 2013; 17 (3): 432-8.

10. D'Orsi E, Brüggemann OM, Diniz CSG, Aguiar JM, Gusman CR, Torres JA. Desigualdades sociais e satisfação das mulheres com o atendimento ao parto no Brasil: estudo nacional de base hospitalar. Cad Saúde Pública. 2014; 30 (Supl. 1): S154-68.

11. Diniz CSG, D'Orsi E, Domingues RMSM, Torres JA, Dias, MAB, Schneck CA. Implementação da presença de acompanhantes durante a internação para o parto: dados da pesquisa nacional Nascer no Brasil. Cad Saúde Pública. 2014; 30 (Supl. 1): S140-53.

12. Lavender T, Hart A, Smyth RM. Effect of partogram use on outcomes for women in spontaneous labour at term. Cochrane Database Syst Rev. 2013; (7): CD005461.
13. Hofmeyr G.J. Evidence-based intrapartum care. Best Pract Res Clin Obstet Gynaecol. 2005; 19 (1): 103-15.

14. Singata M, Tranmer J, Gyte GML. Restricting oral fluid and food intake during labour. Cochrane Database Syst Rev. 2010; (1): CD003930

15. Lawrence A, Lewis L, Hofmeyr GJ, Styles C. Maternal positions and mobility during first stage labour. Cochrane Database Syst Rev. 2013; (8): CD003934.

16. Molina FJ, Sola PA, Lopez E. Pain in the first stage of labor: relationship with the patient's position. J Pain Symptom Management. 2000; 13 (2): 98-103.

17. Cluett ER, Burns E. Immersion in water in labour and birth. Cochrane Database Syst Rev. 2009; (2): CD000111.

18. Barbieri M, Henrique AJ, Chors FM, Maia NL, Gabrielloni MC. Banho quente de aspersão, exercícios perineais com bola suíça e dor no trabalho de parto. Acta Paul Enferm. 2013; 26 (5): 478-84.

19. Osório SMB, Silva Junior LG, Nicolau AIO. Avaliação da efetividade de métodos não farmacológicos no alívio da dor do parto. Rev Rene. 2014; 15 (1): 174-84.

20. Torres JA, Domingues RMSM, Sandall J, Hartz Z, Gama SGN, Theme Filha MM, Schilithz AOC, Leal MC. Cesariana e resultados neonatais em hospitais privados no Brasil: estudo comparativo de dois diferentes modelos de atenção perinatal. Cad Saúde Pública. 2014; 30 (Supl. 1): S220-31.

21. Vogt SE, Silva KS, Dias MAB. Comparação de modelos de assistência ao parto em hospitais públicos. Rev Saúde Pública. 2014; 48 (2): 304-13.

22. Gupta JK, Hofmeyr GJ. Position for women during second stage of labour. (Cochrane Review). Cochrane Database Syst Rev. 2004; (1): CD002006.

23. Moore ER, Bergman N Anderson GC, Medley N. Early skin-to-skin contact for mothers and their healthy newborn infants. Cochrane Database Syst Rev. 2016; 11: CD003519.

24. Rabe H, Reynolds GJ, Diaz-Rosello JL. Early versus delayed umbilical cord clamping in preterm infants. Cochrane Database Syst Rev. 2004; (4): CD003248.

25. Moreira MEL, Gama SGN, Pereira APE, Silva AAM, Lansky S, Pinheiro RS, Gonçalves AC, Leal MC. Práticas de atenção hospitalar ao recém-nascido saudável no Brasil. Cad Saúde Pública. 2014; 30 (Supl.): S128-39

Received on January 29, 2018

Final version presented on October 27, 2018

Approved on November 28, 2018 